\title{
Actividad enzimática de metanótrofos marinos y su uso potencial en biorremediación
}

\section{Enzymatic activity of marine methanotrophs and its potential use in bioremediation}

\author{
Agar A. Inostroza ${ }^{1 *}$, Silvio Pantoja ${ }^{2,3}$ \& Rodrigo R. González ${ }^{1,3}$ \\ ${ }^{1}$ Unidad de Biotecnología Marina, Facultad de Ciencias Naturales y Oceanográficas, Universidad de Concepción, Concepción, \\ Chile. \\ ${ }^{2}$ Departamento de Oceanografía, Universidad de Concepción, Concepción, Chile. \\ ${ }^{3}$ Centro de Investigación Oceanográfica en el Pacífico Sur-Oriental (FONDAP - COPAS), Universidad de Concepción, \\ Concepción, Chile. \\ *E-mail: agar.inostroza@gmail.com
}

\begin{abstract}
RESUMEN
Los metanótrofos son microorganismos con un importante rol en la biogeoquímica del metano en el océano. La enzima metano monooxigenasa soluble (MMOs) es la encargada de realizar la primera oxidación catabólica del metano, pero además es activa sobre compuestos aromáticos policíclicos y una gran variedad de substancias derivadas del petróleo consideradas como contaminantes. Muestras de sedimento fueron incubadas en medio líquido específico con sales minerales de nitrato (NMS) y en presencia de metano como única fuente de carbono para determinar la actividad de MMOs de la comunidad de metanotrófos presentes en esta matriz ambiental. Las muestras fueron obtenidas desde un área con una emanación visible de metano (Isla Mocha) y de dos áreas sin emanación (Bahía Coronel y Golfo de Arauco). Los microorganismos incubados presentes en los sedimentos superficiales de Isla Mocha poseen una actividad de MMOs dos veces mayor en comparación a las actividades obtenidas en cultivos realizados en las mismas condiciones pero utilizando muestras recolectadas desde áreas sin emanación. Se observó además una relación inversa entre la distribución vertical de la actividad de MMOs y la concentración de metano en Isla Mocha, que indica que la emanación de metano podría incrementar la actividad de MMOs de la comunidad metanotrófica presente en el sedimento de Isla Mocha. Considerando el área de influencia de la emanación de metano de Isla Mocha de $400 \mathrm{~m}^{2}$ de playa, la máxima actividad potencial de la MMOs podría transformar diariamente alrededor de $43 \mathrm{Kg}$ de naftaleno, proporcionando así las bases para el desarrollo de tecnologías para depuración microbiana por contaminación de compuestos aromáticos policíclicos.
\end{abstract}

Palabras Clave: Hidrocarburos aromáticos, Isla Mocha, metano, metano monooxigenasa soluble (MMOs).

\begin{abstract}
Methanotrophs are microorganisms with an important role in the biogeochemistry of methane in the ocean. The most important enzyme involved in methane catabolism is the soluble methane monooxygenase (sMMO), being also active on polycyclic aromatic compounds and other oil-derived substances considered pollutants. Sediment samples were incubated in a specific liquid nitrate mineral salt (NMS) medium and in presence of methane as a unique source of carbon to determine sMMO activity of the methanotrophs. Samples were obtained from an area with a visible emanation of methane (Mocha Island) and two areas without emanation (Coronel Bay and Gulf of Arauco). The microorganisms present in the incubations of surface sediments from Mocha Island have a two-fold sMMO activity than the activities obtained in cultures performed under the same conditions but using samples collected from areas without emanation. Moreover, an opposite relationship between sMMO activity and methane concentration was detected in the sediment column, suggesting a positive effect of methane emission on sMMO activity of the methanotroph community of Mocha Island. Considering an area of impact of methane emission in Mocha Island of $400 \mathrm{~m}^{2}$, the maximun potential sMMO activity could daily transform ca. $43 \mathrm{Kg}$ of naphthalene, thus providing basis for the development of technologies for microbial detoxification of polycyclic aromatic molecules.
\end{abstract}

KEYwORDS: Aromatic hydrocarbons, Methane, Mocha Island, soluble methane monooxygenase (sMMO). 


\section{INTRODUCCIÓN}

El ciclo oceánico del metano comprende una serie de reacciones, principalmente mediadas por la comunidad microbiana, que involucran su producción (metanogénesis) y su consumo (metanotrofía). A estas reacciones se suma un conjunto de procesos geológicos tales como fuentes hidrotermales, emanaciones frías (cold seeps), volcanes de lodo y clatratos de metano, que también contribuyen con metano a la columna de agua (Reeburgh et al. 1993; Karl et al. 2008). Gran parte de la producción total de metano está concentrada a lo largo de los márgenes continentales, los cuales aportan un $75 \%$ de las emisiones de este gas a la atmósfera (Bange et al. 1994; Bange et al. 1995), y donde además la actividad tectónica facilita la liberación de metano desde los depósitos de petróleo y gas natural (Tavormina et al. 2008).

El consumo microbiano de metano es realizado, en condiciones aeróbicas por bacterias metanótrofas (Dalton \& Leak 1985; Hanson \& Hanson 1996; Lidstrom 2006), y en condiciones anaeróbicas por consorcios sintróficos de bacterias reductoras de sulfato y arqueas metanótrofas (Dalton \& Leak 1985; Boetius et al. 2000; Raghoebarsing et al. 2006). La importancia ecológica y biogeoquímica de los metanotrófos, un tipo de metilótrofos que utilizan metano como fuente de carbono y energía, radica en que son los únicos microorganismos capaces de transformarlo en agua, dióxido de carbono y biomasa (Whittenbury \& Dalton 1981; Hanson \& Wattenburg 1991; Lidstrom 1991; Hanson \& Hanson 1996). Estos microorganismos son ubicuos, habitan en el límite entre ambientes aeróbicos y anaeróbicos, donde metano y oxígeno están disponibles, jugando un papel esencial en el ciclo global del carbono al limitar la cantidad de metano que es liberado hacia la atmósfera (Hanson \& Wattenburg 1991; Hanson \& Hanson 1996). No obstante, los metanótrofos también son capaces de degradar un gran número de compuestos orgánicos considerados contaminantes, incluyendo compuestos halogenados de bajo peso molecular como el di y tri cloroetileno, di y tri cloroetano, cloruro de vinilo, cloroformo y diclorometano, entre otros (Wackett \& Gibson 1983; Fogel et al. 1986; Green \& Dalton 1989; Brusseau et al. 1990; Alvarez-Cohen \& McCarty 1991; Koh et al. 1994). La primera etapa de la oxidación de metano es llevada a cabo por la enzima metano monooxigenasa (MMO) que cataliza la hidroxilación de la molécula de metano a metanol, aumentando así su solubilidad. La forma soluble de esta enzima (MMOs) se expresa cuando en el medio hay deficiencia o ausencia de cobre (Dalton 1992) y la forma particulada (MMOp) cuando las concentraciones de cobre alcanzan los 0,86 miligramos de cobre por gramo en peso seco de células bacterianas (Dalton 1992; Tsien \& Hanson 1992). La MMOs es más activa que la MMOp en la degradación de compuestos orgánicos halogenados de bajo peso molecular y aromáticos bicíclicos (Lipscomb 1994). Sin embargo, sólo un limitado número de metanótrofos posee la información genética que codifica el gen de la MMOs (Tsien \& Hanson 1992; Dalton 1992; Hanson \& Hanson 1996). La actividad de esta enzima se presenta como un interesante objeto de estudio para la biotecnología marina ya que podría ser utilizada en procesos de biorremediación.

El objetivo del presente trabajo fue cuantificar la actividad de la enzima metano monooxigenasa soluble proveniente de microorganismos cultivados desde sedimentos obtenido de tres zonas de la región del Bío-Bío, Chile, comparando el efecto de una emanación de metano (Isla Mocha) sobre la actividad de MMOs con dos áreas sin emanación (Bahía Coronel y Golfo de Arauco).

\section{MATERIALES Y MÉTODOS}

Áreas De Estudio y Obtención De Muestras

Las muestras se obtuvieron desde la zona centro-sur de Chile, región del Bío-Bío (Fig. 1). Las muestras de sedimento desde las zonas con emanación de metano se obtuvieron con sacatestigos de $40 \mathrm{~mm}$ de diámetro y $30 \mathrm{~cm}$ de largo en primavera (Septiembre 2008) desde cuatro sectores costeros de Isla Mocha (38 $23^{\prime} 06^{\prime \prime}$ S$\left.73^{\circ} 52^{\prime} 00^{\prime \prime} \mathrm{W}\right)$ : tres zonas intermareales denominadas A1

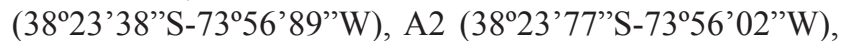

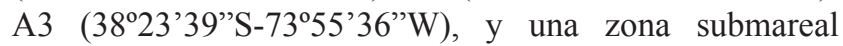
denominada I (38²4'73”S-7356'93”W). Además, se obtuvo sedimento en zonas sin emanación visible de metano desde sitios en Bahía Coronel (36 $58^{\circ} 27^{\prime \prime} \mathrm{S}-73^{\circ} 12^{\prime} 42^{\prime}$ 'W) y Golfo de Arauco (37 $\left.15^{\prime} 23^{\prime \prime} \mathrm{S}-7^{\circ} 16^{\prime} 31^{\prime \prime} \mathrm{W}\right)$ mediante una draga van Veen modificada y submuestreadas con sacatestigos de $40 \mathrm{~mm}$ de diámetro y $6 \mathrm{~cm}$ de largo en invierno (Julio, 2008). Las muestras se seccionaron en estratos de dos centímetros (Tabla 1) y se mantuvieron a 4 ${ }^{\circ} \mathrm{C}$ hasta su posterior análisis.

Con el fin de evaluar el efecto de la atmósfera de metano en la actividad de MMOs, se realizaron incubaciones en duplicado de seis estratos de sedimento entre 8 y $20 \mathrm{~cm}$ de la estación A2 de Isla Mocha (Tabla 1) inoculando en una proporción de 1:100 submuestras de sedimento en un medio líquido especifico para metilotrofos compuesto por sales minerales de nitrato (NMS) sin cobre con las siguientes proporciones de metano: $0,10,20,30,40,50 \% \mathrm{v} / \mathrm{v}$. Las muestras de sedimento se incubaron en oscuridad bajo agitación constante $(200 \mathrm{rpm})$ por 18 días a temperatura ambiente $\left(15^{\circ} \mathrm{C}\right)$ en la Estación de Biología Marina (Dichato) de la Universidad de Concepción. 


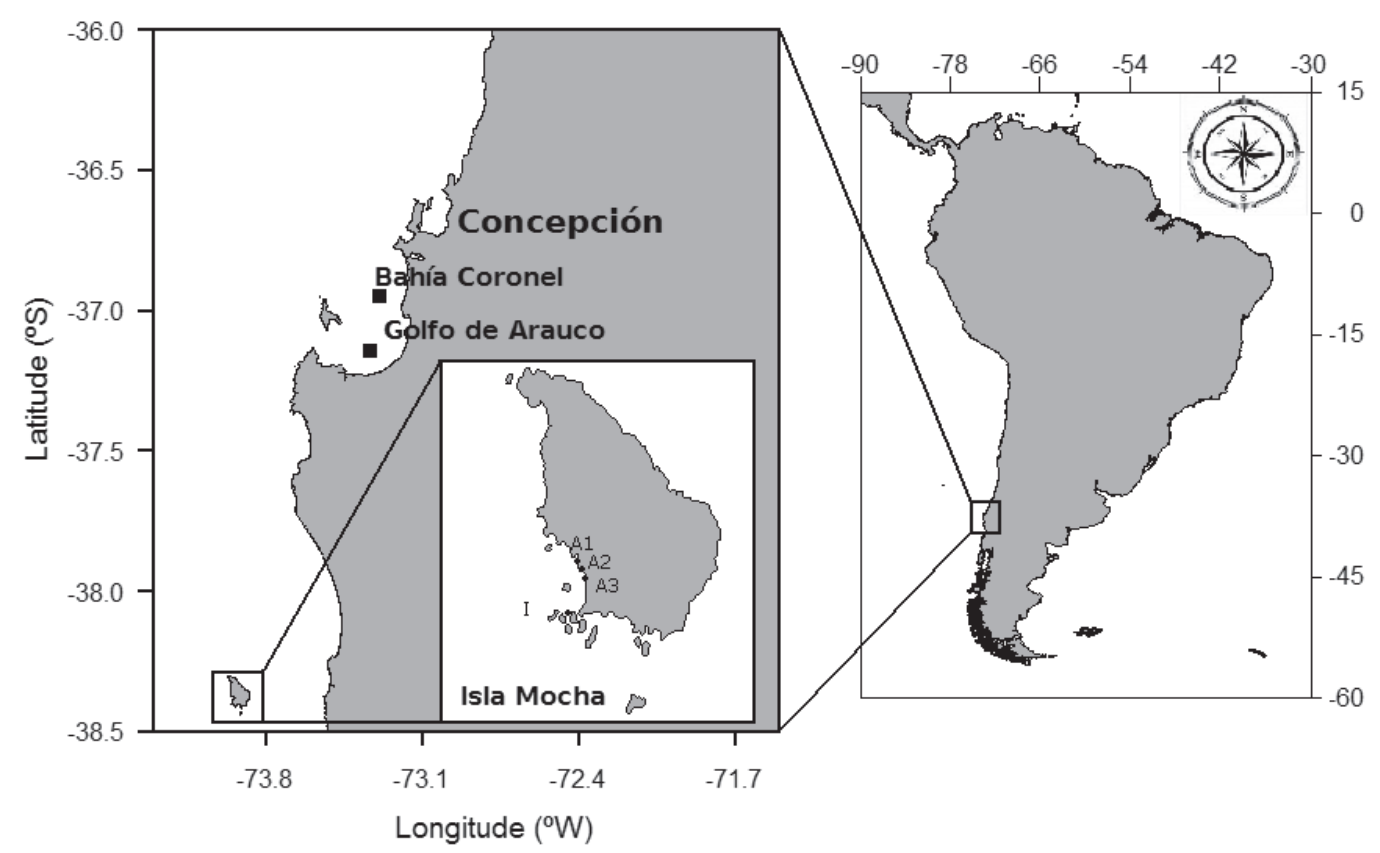

FIGURA 1. Ubicación de las estaciones de muestreo de sedimento en sitios con emanación de metano en Isla Mocha (•), y sin emanación (匹) en Bahía Coronel y Golfo de Arauco.

FIGURE 1. Location of sediment sampling stations in areas with emission of methane in Mocha Island (•), and without emanation $(\boldsymbol{\bullet})$ in Coronel Bay and Gulf of Arauco.

TABLA 1. Sitios de muestreo y secciones de sedimentos utilizados en incubaciones para la determinación de actividad de la enzima metano monooxigenasa soluble (MMOs) en los testigos obtenidos de las áreas de estudio. Sitios A1, A2, A3 e I corresponden a Isla Mocha.

TABLE 1. Sampling sites and sediment sections used for the determination of activity of the soluble enzyme methane monooxygenase (sMMO) in cores collected from the study areas. Sites A1, A2, A3 and I correspond to Mocha Island.

\begin{tabular}{llllll}
\hline $\begin{array}{l}\text { Estación A1 } \\
(\mathrm{cm})\end{array}$ & $\begin{array}{l}\text { Estación A2 } \\
(\mathrm{cm})\end{array}$ & $\begin{array}{l}\text { Estación A3 } \\
(\mathrm{cm})\end{array}$ & $\begin{array}{l}\text { Estación I } \\
(\mathrm{cm})\end{array}$ & $\begin{array}{l}\text { Golfo de Arauco } \\
(\mathrm{cm})\end{array}$ & $\begin{array}{l}\text { Bahía Coronel } \\
(\mathrm{cm})\end{array}$ \\
\hline $0-2$ & $0-2$ & $0-2$ & $0-2$ & $0-2$ & $0-2$ \\
$2-4$ & $2-4$ & $2-4$ & & $2-4$ & $2-4$ \\
$4-6$ & $4-6$ & $4-6$ & & $4-6$ & $4-6$ \\
$6-8$ & $6-8$ & $6-8$ & & \\
$8-10$ & $8-10$ & $8-10$ & & \\
$10-12$ & $10-12$ & $10-12$ & & \\
$12-14$ & $12-14$ & $12-14$ & & \\
$14-16$ & $14-16$ & 15 & & \\
$16-18$ & $16-18$ & & & \\
$18-20$ & $18-20$ & & & \\
$20-22$ & & & & \\
$22-24$ & & & & \\
$24-26$ & & & & \\
\hline
\end{tabular}


Submuestras de sedimentos $(0-26 \mathrm{~cm}$ en A1; 0-20 cm en A2; $0-15 \mathrm{~cm}$ en A3 y $0-2 \mathrm{~cm}$ en I) de las cuatro estaciones de Isla Mocha (Tabla 1) se incubaron en duplicado en medio de cultivo líquido NMS sin cobre, con una atmósfera de $45 \% \mathrm{v} / \mathrm{v}$ metano, y en una atmósfera de $45,47,5$ y $50 \% \mathrm{v} / \mathrm{v}$ de metano se incubaron sedimentos superficiales $(0-6 \mathrm{~cm})$ de Bahía Coronel y Golfo de Arauco (Tabla 1) bajo las mismas condiciones de cultivos descritas anteriormente. Además se realizaron incubaciones sin metano con sedimento de cada sitio.

La determinación de la actividad enzimática de la MMOs en las incubaciones se realizó en la Unidad de Biotecnología Marina de la Universidad de Concepción utilizando una mezcla de reacción que contenía $1 \mathrm{~mL}$ de cultivo, $25 \mathrm{mM}$ de formato sódico y $1 \mathrm{~mL}$ de solución saturada y filtrada de naftaleno. La mezcla se incubó agitando a $200 \mathrm{rpm}$ por tres horas, a temperatura ambiente. Al término de la incubación se agregó $100 \mu \mathrm{L}$ de $1 \%$ o-dianisidina a la mezcla de reacción como reactivo cromogénico (Wackett \& Gibson 1983; Brusseau et al. 1990). El producto formado entre la amina aromática (o-dianisidina) y $\alpha$-naftol (naftaleno hidroxilado por la enzima MMOs) corresponde a diazo 2,1-dihidroxi 4,4-diazoniodimetoxy bencidina el cual fue estabilizado con $400 \mu \mathrm{L}$ de ácido acético glacial. La absorbancia del producto se midió a $440 \mathrm{~nm}$ y la actividad enzimática de MMOs se calculó utilizando el coeficiente de extinción molar del compuesto diazo formado $\left(\xi=38.000 \mathrm{M}^{-1} \mathrm{~cm}^{-1}\right.$, Wackett \& Gibson 1983; Brusseau et al. 1990).

Los resultados de actividad enzimática fueron analizados usando la prueba no paramétrica de Kruskal-Wallis, con el fin de comparar múltiples muestras independientes y discriminar acerca del grado de similitud o disimilitud entre muestras.

\section{RESULTADOS Y DISCUSIÓN}

INCUBACIONES CON CONCENTRACIONES CRECIENTES DE METANO En las incubaciones realizadas con concentraciones crecientes de metano, la mayor actividad de MMOs se determinó en cultivos de sedimento con metano al $40 \% \mathrm{v} / \mathrm{v}$ en los estratos $14-16$ y $18-20 \mathrm{~cm}$, con $31,9 \pm 6,6$ y $26,9 \pm 5,2 \mathrm{nmol}$ naftol (g sedimento húmedo min)-1, respectivamente (Fig. 2). Los valores máximos son significativamente mayores $(p<0,05)$ que los determinados en las incubaciones realizadas con un $10,20,30$ y $50 \%$ v/v de metano (Fig. 2). Los valores promedios indican un incremento de la actividad MMOs en todos los cultivos incubados con un $10 \% \mathrm{v} / \mathrm{v}$ de metano, seguido de una disminución significativa $(p<0,05)$ para las concentraciones ensayadas con un 20 y $30 \% \mathrm{v} / \mathrm{v}$ de metano (Fig. 2).
Los resultados de la actividad de MMOs determinada en incubaciones con concentraciones crecientes de metano en la estación A2 de Isla Mocha muestran diferencias significativas $(p>0,05)$ entre estratos de sedimentos incubados para la misma concentración de metano utilizada como fuente de carbono (Fig. 2). Estos resultados sugieren al menos dos posibles causas. La primera se relaciona con la presencia de al menos dos ensambles microbianos que metabolizan metano a distintas tasas. El primero se encuentra en los primeros tres estratos incubados $(8-14 \mathrm{~cm})$ el cual presenta bajas actividades enzimáticas con respecto al segundo grupo presente en los últimos estratos incubados $(16-20 \mathrm{~cm})$ para la misma concentración de metano $(40 \%$ v/v) utilizada como fuente de carbono (Fig. 2). La segunda posibilidad es que esta diferencia de actividad de MMOs se deba a una diferencia en el número de microorganismos presentes en las muestras de sedimento incubado.

\section{SEDIMENTO SUPERFICIAL}

La actividad de MMOs determinada en cultivos de sedimento superficial de Bahía Coronel y Golfo de Arauco fue mayor en cultivos con $45 \% \mathrm{v} / \mathrm{v}$ de metano (Fig. 3a, b), con valores máximos promedios de 1,6 $\pm 0,5$ y 1,7 $\pm 0,6 \mathrm{nmol}$ naftol (g sedimento húmedo $\min )^{-1}$, respectivamente.

La comparación de la actividad de MMOs de los cultivos de sedimento superficial $(0-6 \mathrm{~cm})$ de las áreas estudiadas de Isla Mocha, Bahía Coronel, y Golfo de Arauco resulta en una mayor actividad en la estación A1 de Isla Mocha con un valor acumulado para los tres estratos de 20,9 nmol de naftol (g sedimento húmedo min) ${ }^{-1}$ (Tabla 2). Esta observación es consistente con el perfil de actividad en profundidad observado para la estaciones de Isla Mocha (Fig. 4), en donde la mayor actividad de MMOs se determinó en cultivos de los estratos $6-10 \mathrm{~cm}$, aunque las diferencias fueron menos dramáticas en las estaciones de Bahía Coronel y Golfo de Arauco (datos no mostrados). En resumen, la actividad enzimática de MMOs determinada en los cultivos de sedimento superficial $(0-6 \mathrm{~cm})$ de todas las estaciones de Isla Mocha fue significativamente mayor $(p<0,05)$ a la actividad determinada en las estaciones de Bahía Coronel y Golfo de Arauco (Tabla 2).

De las determinaciones de la actividad de MMOs en la literatura existen tres trabajos asociados al análisis cualitativo de esta actividad enzimática con el fin de detectar y aislar cepas de metanotrófos que expresan el gen de la MMOs (Wakett \& Gibson 1983; Brusseau et al. 1990; Graham et al. 1992). Por otro lado, los trabajos que miden esta actividad en forma cuantitativa son dos, donde la determinación de actividad de MMOs para ambos trabajos se realiza en cultivos incubados desde material sólido de aguas subterráneas de un acuífero (Bowman \& Sayler 1994; Begonja \& Hrsk 2001). Las condiciones de cultivo cuentan 
con una atmósfera de metano-aire de 1:4 y 1:3, por 40 y 14 días respectivamente. Para comparar los valores de actividad de MMOs se supone que un miligramo de peso seco de células bacterianas contiene entre 2 y 8 nmoles de ATP (Karl 1980), y la fracción proteica de una célula bacteriana equivale al $60 \%$ de su peso seco (Simon \& Azam 1989). La mayor actividad de MMOs determinada en incubaciones de sedimentos superficiales de la estación A1 de Isla Mocha (con emanación de metano), correspondiente a 20,9 nmol de naftol (g sedimento húmedo $\mathrm{min})^{-1}$, contiene una biomasa de 28,9 nmol ATP g-1 (data no publicada, R González). Esta actividad corresponde a 289,3 nmol naftol (mg proteína h) ${ }^{-1}$, consistente con los máximos valores de actividad de MMOs

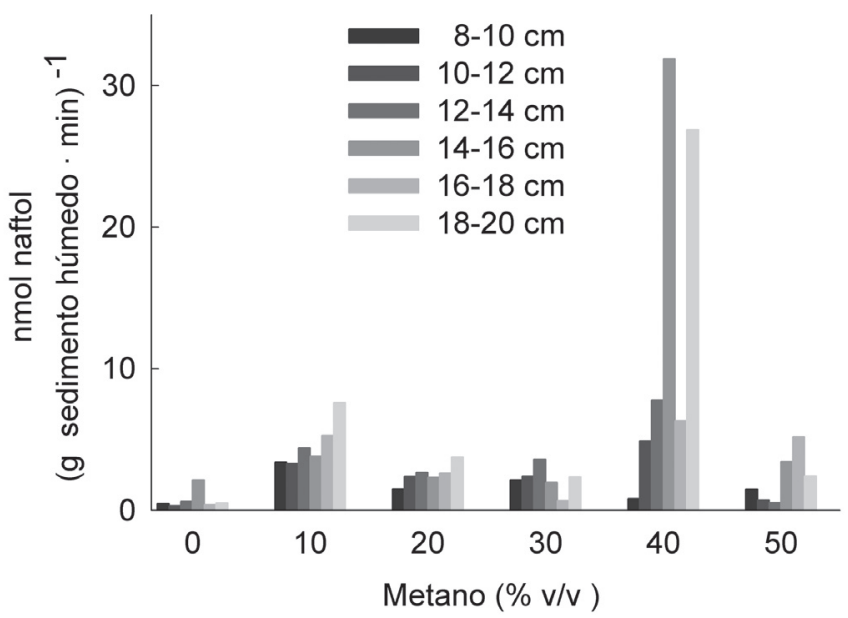

FIgURA 2. Actividad de MMOs en cultivos de seis estratos de sedimento de estación A2 de Isla Mocha bajo diferentes atmósferas de metano.

FIGURE 2. Activity of sMMO in cultures of six layers of sediment of A2 station of Mocha Island under different methane atmospheres. reportados por Bowman \& Sayler (1994) y Begongia \& Hrsk (2000) que corresponden a 300 y 560 nmol de naftol (mg proteína $\mathrm{h})^{-1}$ respectivamente. En ambos trabajos se buscó optimizar la actividad de MMOs y medir el efecto de los nutrientes y la concentración de metano en la actividad de esta enzima.

\section{Perfiles de actividad en testigos de Sedimento}

La actividad de MMOs en el sedimento arenoso de las estaciones de Isla Mocha (Fig. 4a) fue máxima en estratos entre 6 y $10 \mathrm{~cm}$ de profundidad para las estaciones A1, A2, y A3, con valores mayores a los $20 \mathrm{nmol}$ naftol (g sedimento húmedo $\min )^{-1}$.

La distribución de la actividad de MMOs en la sección vertical del sedimento en las tres estaciones de Isla Mocha (Fig. 4a) muestra una relación inversa con la distribución de la concentración de metano (Fig. 3b) obtenido para la estación A2 (emanación activa) durante el mismo programa de muestreo del presente trabajo (Jessen et al. 2011). Así, la máxima actividad de MMOs obtenida en los primeros 10 $\mathrm{cm}$ coincide con una mínima concentración de metano (Fig. $4 \mathrm{a}$ y b). En profundidad, la mínima actividad de MMOs asociada a un máximo de metano (Fig. 4a y b) podría deberse principalmente a la reducción de la concentración de oxígeno en el sedimento más profundo. Un déficit de oxígeno afecta la primera vía metabólica del metano, específicamente el centro activo binuclear de hierro de la enzima MMOs (Wackett \& Gibson 1983; Brusseau et al. 1990; Hanson \& Hanson 1996; Stahl et al. 2001; Bowman 2006). La disminución de la actividad de MMOs con la profundidad también ha sido observada en sedimentos donde existe una transición entre la oxidación aeróbica a una anaeróbica del metano, la que es llevada a cabo por consorcios sintróficos de bacterias reductoras de sulfato y arqueas metanótrofas (Boetius et al. 2000; Raghoebarsing et al. 2006; Knittel \& Boetius 2009).

TABla 2. Actividad enzimática de MMOs en nmol naftol ( $\mathrm{g}$ sedimento húmedo min) ${ }^{-1}$ determinada en cultivos de sedimento superficial (estratos 0-2, 2-4, y 4-6 cm) en las estaciones de Isla Mocha, Bahía Coronel y Golfo de Arauco. Actividad acumulada fue calculada como la suma de las actividades de los tres estratos. Mediciones en duplicado fueron llevadas a cabo para cada estrato.

TABLE 2. sMMO enzymatic activity in nmol naphthol (min $g$ wet sediment) ${ }^{-1}$ determined in cultures of surface sediment (strata $0-2,2-4$, and 4-6 cm) at stations of Mocha Island, Coronel Bay and Gulf of Arauco. Cumulative activity was calculated as the sum of the activities of the three strata. Duplicated measurements were conducted in each section.

\begin{tabular}{llllll}
\hline & Estación A1 & Estación A2 & Estación A3 & Bahía Coronel & Golfo de Arauco \\
\hline Actividad acumulada MMOs & 20,9 & 12,7 & 14,8 & 4,7 & 5,2 \\
Promedio actividad entre estratos & $7 \pm 12,1$ & $4,2 \pm 5,6$ & $4,9 \pm 4,3$ & $1,6 \pm 0,5$ & $1,7 \pm 0,6$ \\
\hline
\end{tabular}



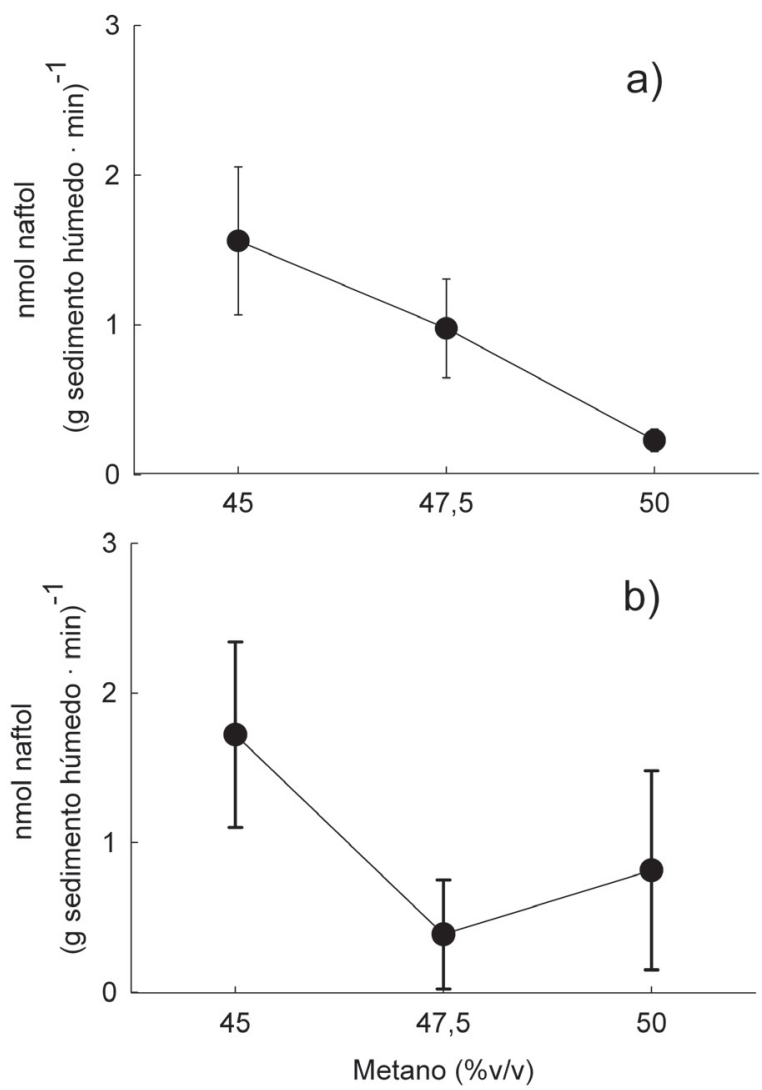

Figura 3. Promedio de actividad de MMOs de metanótrofos inoculados con distintas concentraciones de metano en los 0-6 cm de los sedimentos de (a) Bahía Coronel y (b) Golfo de Arauco.

FIGURE 3. Average of activity of sMMO of methanotrophs inoculated with different concentrations of methane in $0-6 \mathrm{~cm}$ of sediments of (a) Coronel Bay and (b) Gulf of Arauco.

\section{COMPARACIÓN DE LA ACTIVIDAD ENTRE SITIOS DE MUESTREO}

La actividad promedio determinada en incubaciones de los 3 primeros estratos del sedimento de Isla Mocha, resultó ser 2,5 veces mayor $(p<0,05)$ que la obtenida para los sedimentos de Bahía Coronel y Golfo de Arauco (Tabla 2). Esta diferencia en la actividad es consistente con que la presencia de metanótrofos ha sido asociada a sedimentos de granos gruesos en zonas expuestas a emanaciones de metano (Anthony 1982; Childress et al. 1986; Schmaljohann 1991; Vacelet et al. 1996) como por ejemplo los encontrados en Isla Mocha, en contraste con el sedimento fino presente en las áreas sin emanación (Bahía Coronel, Golfo de Arauco).

Estos resultados también sugieren un efecto positivo de la emanación activa de metano sobre la expresión de la actividad de la MMOs de la comunidad metanotrófica que habita en el sedimento de Isla Mocha y concuerdan con estudios asociados a zonas con emanaciones de metano que demuestran una influencia positiva sobre la selección de metanótrofos principalmente del tipo II que en su mayoría expresan la actividad MMOs (Valentine et al. 2001; Yan et al. 2006; Elvert \& Niemann 2007; Lösekann et al. 2007; Tavormina et al. 2008).

Así mismo, los valores bajos y nulos de actividad de MMOs en algunos estratos del sedimento no indican necesariamente ausencia de microorganismos metanotróficos, sino la ausencia de la expresión de MMOs en condiciones de cultivo.

La mayor actividad enzimática de MMOs determinada en cultivos obtenidos desde la emanación activa de metano en la Isla Mocha indicaría que la comunidad microbiana asociada, posee un mayor potencial biotecnológico para ser utilizada en técnicas y/o procesos de biorremediación debido a la capacidad de la MMOs para incrementar la solubilidad de los compuestos que utiliza como sustrato (Wackett \& Gibson 1983; Fogel et al. 1986; Green \& Dalton 1989; Brusseau et al. 1990; Alvarez-Cohen \& McCarty 1991; Koh et al. 1994). A fin de evaluar el impacto potencial del área de influencia de emanaciones intermareales (alrededor de $400 \mathrm{~m}^{2}$, Jessen et al. 2011), estimamos la tasa de transformación de compuestos aromáticos de 10 carbonos en los primeros diez centímetros de sedimento. Este bloque superficial de sedimento podría transformar potencialmente, al máximo de su actividad determinada de 26,1 nmol naftol (g sedimento húmedo · min $)^{-1}$ y asumiendo una densidad del sedimento marino de $2 \mathrm{~g} \cdot \mathrm{cm}^{-3}$ (Arnarson \& Keil 2001), alrededor de 43,4 Kg Naftaleno $\cdot$ día $^{-1}$. Este ejercicio sugiere fuertemente que el uso de esta actividad enzimática podría ser considerado en el desarrollo de tecnologías para depurar zonas contaminadas por derrames $\mathrm{y} / \mathrm{u}$ otros eventos ambientales, como por ejemplo la recuperación de áreas industrializadas que involucren la contaminación por compuestos aromáticos policíclicos.

En conclusión, la actividad de MMOs observada en cultivos de sedimento de Isla Mocha, Bahía Coronel, Golfo de Arauco demuestra que las cepas de metanótrofos tienen la potencialidad metabólica para degradar naftaleno y por lo tanto, de degradar otros compuestos aromáticos contaminantes. Así mismo, la mayor actividad enzimática de MMOs obtenida para los sedimentos provenientes de las estaciones de Isla Mocha sugiere que estos sedimentos expuestos a emanaciones de metano serían óptimos para el cultivo y la obtención de cepas de microorganismos metanotróficos capaces de degradar compuestos aromáticos de bajo peso molecular. El protocolo de este trabajo representa una herramienta bioquímica estandarizada para la búsqueda de especies de microorganismos marinos potencialmente utilizables en el área de la biotecnología marina y específicamente en procesos de biorremediación ambiental. 

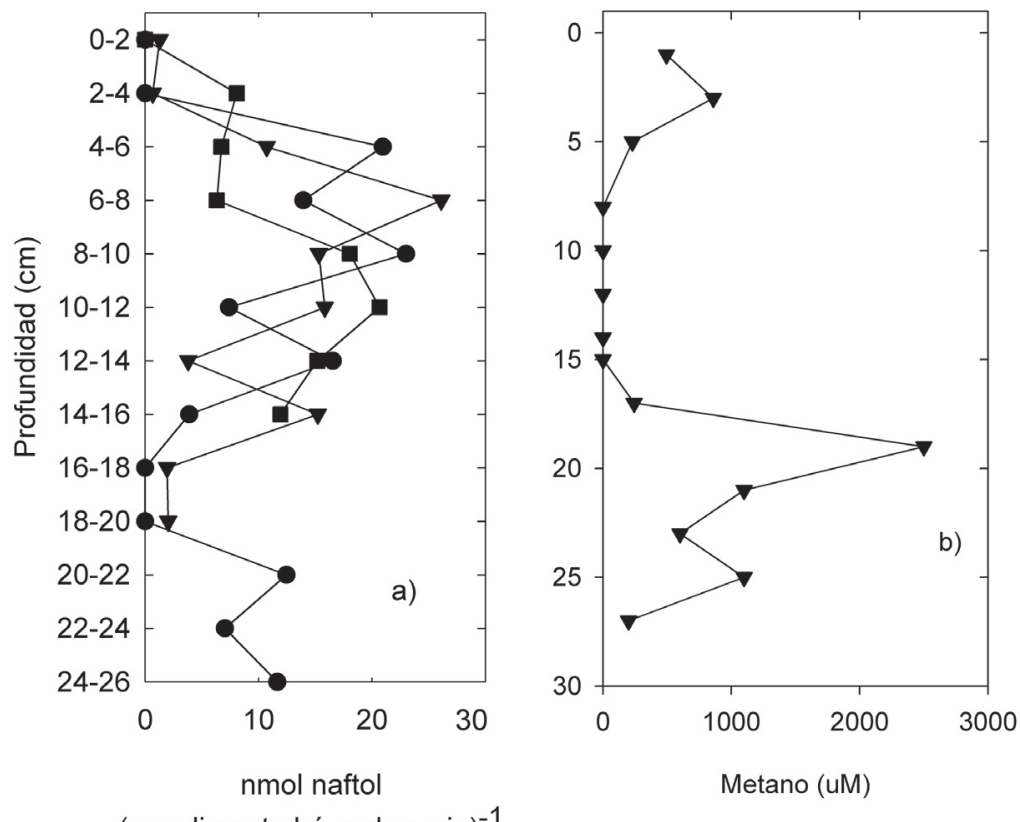

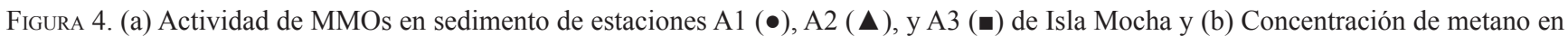
testigo de sedimento de la estación A2 ( $\mathbf{\Delta})$ de Isla Mocha (Tomado de Jessen et al. 2010).

Figure 4. (a) Activity of sMMO in the sediment of stations A1 (•), A2 ( $\mathbf{\Delta})$, and A3 ( $\bullet$ ) of Mocha Island and (b) Concentration of methane in sediment cores of Station A2 ( $\mathbf{\Delta})$ of Mocha Island (From Jessen et al. 2011).

\section{AGRADECIMIENTOS}

Agradecemos a Tania León y Gerdhard Jessen por proporcionar datos de biomasa microbiana y de concentración de metano utilizados en este trabajo, a Oliver Alarcón y María José Zúñiga por su colaboración en aspectos experimentales y teóricos de este trabajo, al personal de la Estación de Biología Marina de Dichato de la Universidad de Concepción, y al equipo de terreno de Isla Mocha por la ayuda proporcionada durante las campañas (R Castro, J Gutiérrez, M Gutiérrez, T León, L Núñez, J Sellanes, N Valdés), así como el apoyo logístico de Anselmo Astete y Lilian Vera de Isla Mocha. Esta investigación fue financiada por el proyecto FONDECYT 1080623.

\section{BIBLIOGRAFIA}

Alvarez-Cohen, L. \& Mccarty, P. 1991. Effects of toxicity, aeration and reductant supply on trichloroethylene transformation by a mixed methanotrophic culture. Applied and Environmental Microbiology 57: 228-235.

AnTHONY, C. 1982. Methanogens and methanogenesis. In: Anthony C (ed). The biochemistry of methylotrophs 11: 296-327. Academic Press, London.

Arnarson, T. \& KeIL, R. 2001. Organic-mineral interactions in marine sediments studied using density fractionation and
X-ray photoelectron spectroscopy. Organic Geochemistry 32: 1401-1415.

Bange, H., Rapsomanikis, S. \& Andreae, M. 1994. Methane in the Baltic and north seas and a reassessment of the marine emission of methane. Global Biogeochemical Cycles 4: 465-480.

Bange, H., Rapsomanikis, S. \& Andreae, M. 1995. The aegean sea as a source of atmospheric nitrous oxide and methane. Elsevier Science Marine Chemistry 53: 41-49.

BegOnJa, A. \& Hrsak, D. 2001. Effect of growth conditions on the expression of soluble methane monooxygenase. Food Technology and Biotechnology 39: 29-35.

Boetius, A., Ravenschlag, K., Schubert, C., Rickert, D., Widdel, F., Gieseke, A., Amann, R., Jörgensen, B., Witte, U. \& Pfannkuche, O. 2000. Marine microbial consortium apparently mediating anaerobic oxidation of methane. Nature 407: 623-625.

Bowman, J. \& SAYler, G. 1994. Optimization and maintenance of soluble methane monooxygenase activity in Methylosinus trichosporium OB3b. Biodegradation 5: 1-11.

Bowman, J. 2006. The Methanotrophs. The families methylococcaceae and methylocystaceae. In: Dworkin M, S Falkow, E Rosenberg, K Schleifer \& E Stackebrandt (eds). The prokaryotes 5: 266-289. Academic Press, New York.

Brusseau, G., Tsien, H., Hanson, R. \& Wackett, L. 1990. Optimization of trichloroethylene oxidation by methanotrophs and the use of a colorimetric assay to detect soluble methane monooxygenase activity. Biodegradation 1: $19-29$. 
Childress, J., Fisher, C., Brooks, J., Kennicutt, M., Bidigare, R. \& ANDERson, A. 1986. A methanotrophic marine molluscan (Bivalvia, Mytilidae) symbiosis: mussels fueled by gas. Science 233: 1306-1308.

Dalton, H. \& LeAK, D. 1985. Methane oxidation by microorganisms. In: Poole S \& C Dow (eds). Microbial gas metabolism: mechanistic metabolic and biotechnological aspects 4: 173-200. Academic Press, Michigan.

Dalton, H. 1992. Methane oxidation by methanotrophs. In: Murrell J \& H Dalton (eds). Methane and methanol utilizers 11: 85-114. Plenum Press, New York.

Elvert, M. \& NiemanN, H. 2007. Occurrence of unusual steroids and hopanoids derived from aerobic methanotrophs at an active marine mud volcano. Organic Geochemistry 39: 167-177.

Fogel, M., Taddeo, A., \& Fogel, S., 1986. Biodegradation of chlorinated ethenes by a methane-utilizing mixed culture. Applied and Environmental Microbiology 51: 720-724.

Graham, D., Korich, D., Leblanc, R., Sinclair, N., \& Arnold. R., 1992. Applications of a colorimetric plate assay for soluble methane monooxygenase activity. Applied and Environmental Microbiology 58: 2231-2236.

Green, H. \& Dalton, H. 1989. Substrate specificity of soluble methane monooxygenase: mechanistic implications. The Journal of Biological Chemistry 264: 17698-17703.

HANSON, R. \& WattenBuRG, E. 1991. Ecology of methane-oxidizing bacteria. In: Goldberg I \& J Rokem (eds). Biology of methylotrophs 4: 325-349. Butterworths Publishers, London.

HAnson, R. \& Hanson, T. 1996. Methanotrophic bacteria. Microbiological Reviews 60: 439-471.

Hanson, R. 1998. Ecology of methylotrophic bacteria. In: Burlague R, RAtlas, D Sthal, G Geesey \& G Sayler (eds). Techniques in microbial ecology 6: 137-161. Oxford University Press, Inc.

Jessen, G., Pantoja, S., Gutiérrez, M., Quiñones, R., GonzÁlez, R., Sellanes, J. \& Hinrichs K. 2011. Methane in shallow cold seeps at Mocha Island off central Chile. Continental Shelf Research 31: 574-581.

KARL, D. 1980. Cellular nucleotide measurements and applications in microbial ecology. Microbiological Reviews 44: 739796.

Karl, D., Beversdorf, L., Buörkman, K., Matthew, M., Church, J., Martinez, A. \& Delong, E. 2008. Aerobic production of methane in the sea. Nature Geoscience 1: 473-478.

KNittel, K. \& Boetius, A. 2009. Anaerobic oxidation of methane: progress with an unknown process. The Annual Review of Microbiology 63: 311-334.

Koh, S., Bowman, J., \& SaYler, G. 1994. Soluble methane monooxygenase activity in methylomonas methanica 68 1 isolated from a trichloroethylene-contaminated aquifer. In: Hinchee R, A Leeson, L Semprini \& S Ong (Eds). Bioremediation of chlorinated and polycyclic aromatic hydrocarbon compounds 2: 327-332. Lewis Publishers, New York.

Lidstrom, M. 1991. Aerobic methylotrophic prokaryotes. In: Dworkin M, S Falkow, E Rosenberg, K Schleifer \& E Stackebrandt (eds). The prokaryotes 2: 618-634. SpringerVerlag, New York.
Lipscomb, J. 1994. Biochemistry of the Soluble Methane Monooxygenase. Annual Review of Microbiology 48: 371-399.

Lösekann, T., Knittel, K., Nadalig, T., Fuchs, B., Niemann, H., Boetius, A. \& Amann, R. 2007. Diversity and abundance of aerobic and anaerobic methane oxidizers at the Häakon Mosby mud volcano, Barents Sea. Applied and Environmental Microbiology 73: 3348-3362.

Raghoebarsing, A., Pol, A., Pas-Schoonen, K., Smolders, A., Ettwig, K., Rijpstra, W., Shouten, S., Damsté, J., Op Dem Camp, H., Jetten M., \& Strous, M. . 2006. A Microbial consortium couples anaerobic methane oxidation to denitrification. Nature 440: 918-919.

Reeburgh, W., Whalen, S. \& Whalen, M. 1993. The role of methylotrophy in the global methane budget. In: Murrell J \& D Kelly (eds). Microbial growth on C-1 compounds 1: 1-14. Intercept Press, Andover, United Kingdom.

Schmaljohann, R. 1991. Oxidation of Various potential energy sources by the methanotrophic endosymbionts of Siboglinum poseidoni (Pogonophora). Marine Ecology Progress Series 76: 143-148.

Simon, M. \& Azam, F. 1989. Protein contein synthesis rates of planktonic marine bacteria. Marine Ecology Progress Series 51: 201-213.

Stahl, S., Wilson, F., Merkxi, M., Klinman, J. \& Lippard, S. 2001. Oxygen kinetic isotope effects in soluble methane monooxygenase. The Journal of Biological Chemistry 276: 4549-4553.

Tavormina, P., Ussler, W. \& Orphan, V. 2008. Planktonic and sediment-associated aerobic methanotrophs in two seep systems along the north american margin. Applied and Environmental Microbiology 74: 3985-3995.

Tsien, H. \& Hanson, R. 1992. Soluble methane monooxygenase component $\mathrm{B}$ gene probe for identification of methanotrophs that rapidly degrade trichloethylene. Applied and Environmental Microbiology 58: 953-960.

Vacelet, J., Fiala-Medioni, A., Fisher, C. \& Boury-Esnault, N. 1996. Symbiosis between methane-oxidizing bacteria and a deep-sea carnivorous cladorhizid sponge. Marine Ecology Progress Series 145: 77-85.

Valentine, D., Blanton, D., Reeburgh, W. \& Kastner, M. 2001. Water column methane oxidation adjacent to an area of active hydrate dissociation, river basin. Geochimica et Cosmochimica Acta 65: 2633-2640.

Wackett, L. \& Gibson, D. 1983. Rapid Method for Detection and quantitation of hydroxylated aromatic intermediates produced by microorganisms. Applied and Environmental Microbiology 45: 1144-1147.

Whittenbury, R., and Dalton, H. 1981. The methylotrophic bacteria. In: Starr M, H Stolph, H G Trupper, A Balows, \& H Schlegel (eds). The prokaryotes: a handbook on habitats, isolation and identification of bacteria 2: 894902. Springer-Verlag. Berlin.

Yan, T., Ye, Q., Zhou, J. \& Zhang, C. 2006. Diversity of functional genes for methanotrophs in sediments associated with gas hydrates and hydrocarbon seeps in the Gulf of Mexico. FEMS Microbiology Ecology Journal 57: 251-259. 